\title{
Real-Time Pore Pressure Detection: Indicators and Improved Methods
}

\author{
Jincai Zhang ${ }^{1,2}$ and Shangxian Yin ${ }^{2}$ \\ ${ }^{1}$ Geomech Energy, Houston, TX, USA \\ ${ }^{2}$ North China Institute of Science and Technology, Yanjiao, Beijing, China \\ Correspondence should be addressed to Jincai Zhang; zhangjincai@yahoo.com and Shangxian Yin; yinshx03@126.com
}

Received 6 June 2017; Accepted 1 August 2017; Published 27 September 2017

Academic Editor: Fengshou Zhang

Copyright (c) 2017 Jincai Zhang and Shangxian Yin. This is an open access article distributed under the Creative Commons Attribution License, which permits unrestricted use, distribution, and reproduction in any medium, provided the original work is properly cited.

\begin{abstract}
High uncertainties may exist in the predrill pore pressure prediction in new prospects and deepwater subsalt wells; therefore, realtime pore pressure detection is highly needed to reduce drilling risks. The methods for pore pressure detection (the resistivity, sonic, and corrected $d$-exponent methods) are improved using the depth-dependent normal compaction equations to adapt to the requirements of the real-time monitoring. A new method is proposed to calculate pore pressure from the connection gas or elevated background gas, which can be used for real-time pore pressure detection. The pore pressure detection using the logging-whiledrilling, measurement-while-drilling, and mud logging data is also implemented and evaluated. Abnormal pore pressure indicators from the well logs, mud logs, and wellbore instability events are identified and analyzed to interpret abnormal pore pressures for guiding real-time drilling decisions. The principles for identifying abnormal pressure indicators are proposed to improve real-time pore pressure monitoring.
\end{abstract}

\section{Introduction}

Many deep sedimentary formations have abnormal pore fluid pressures or overpressures. Abnormal pore pressures may cause serious drilling incidents (e.g., fluid influx, kicks, and even blowouts), if these abnormal pressures are not accurately predicted in predrill stage or detected in realtime drilling. Pore pressure analysis mainly includes three aspects, that is, predrill pore pressure prediction, real-time pore pressure detection, and postwell analysis. If predrill pore pressure prediction has big uncertainty, real-time pore pressure detection is needed to update predrill pore pressure prediction and advise drilling operations in real-time to adjust the mud weight to reduce drilling risks. Real-time pore pressure detection generally relies on the following available data for analyses and interpretations when they are available: logging-while-drilling (LWD), measurement-while-drilling (MWD), measured pore pressures, drilling parameters, and mud logging data.

\section{Methods of Real-Time Pore Pressure Detection}

Different methods for pore pressure prediction have been proposed based on resistivity, sonic transit time (or interval velocity), and other petrophysical data (e.g., [1-10]). This paper will not focus on pore pressure prediction but on realtime detection. For real-time pore pressure detection, the pore pressure calculating methods need to be adapted to fit the real-time needs. In the following sections, methods for real-time pore pressure detection are implemented based on the shale properties with improved normal compaction trend lines.

2.1. Resistivity Method. Resistivity logging data can be used to calculate pore pressure in shales. Eaton [2] proposed the following empirical equation to estimate pore pressure:

$$
P_{\mathrm{pg}}=\mathrm{OBG}-\left(\mathrm{OBG}-P_{\mathrm{ng}}\right)\left(\frac{R}{R_{n}}\right)^{n},
$$


where $P_{\mathrm{pg}}$ is the pore pressure gradient; $P_{\mathrm{ng}}$ is the normal pore pressure gradient; $R$ is the measured shale resistivity; OBG is the overburden stress gradient; $R_{n}$ is the shale resistivity in the normal pressure condition; $n$ is an exponent (may vary from 0.6 to 1.5 and normally $n=1.2$ ).

To use Eaton's resistivity method for real-time pore pressure calculation, we need to determine the shale resistivity in the normal compaction condition. The following depthdependent equation can be used to calculate the normal compaction trend (NCT):

$$
R_{n}=R_{0} e^{b Z},
$$

where $R_{0}$ is the resistivity value when $Z=0 ; b$ is a compaction parameter; $Z$ is the true vertical depth below the mudline (i.e., the surface level for onshore drilling or the sea floor in offshore drilling).

Determining the NCT is critically important for the real-time pore pressure detection. A case study [9] is used here to illustrate how to obtain the depth-dependent NCT parameters for real-time applications (Figure 1). We firstly calculate the NCT based on (2) and then estimate the pore pressure from Eaton's equation (see (1)), as shown in Figure 1. The calculated pore pressure needs to be calibrated to the measured pore pressure data (e.g., the RTF in Figure 1). Based on this calibration we can adjust the parameters $R_{0}$ and $b$. When the calculated pore pressure matches the measured pore pressure, it indicates that the NCT (i.e., the parameters $R_{0}$ and $b$ ) is applicable for the real-time pore pressure detection in this area. Certainly, this NCT is also needed to adjust based on the pore pressure indicators in the real-time drilling, which will be discussed later. Therefore, prior to the real-time pore pressure detection, a critical step is to determine the NCT from the offset wells. The formation resistivity may be affected by salinity, anisotropy, and temperature; therefore, corrections are needed when these effects are profound.

It should be noted that the NCT may have different set of calibration parameters for different offset wells. In this case, the calibration parameters in the closer well or wells should be used for the real-time well and then be adjusted based on the pore pressure indicators shown in the real-time drilling.

2.2. Sonic Velocity Method. Pore pressure gradient can also be calculated from the sonic method [11]:

$$
P_{\mathrm{pg}}=\mathrm{OBG}-\left(\mathrm{OBG}-P_{\mathrm{ng}}\right)\left(\frac{\Delta t_{n}}{\Delta t}\right)^{m},
$$

where $\Delta t$ is the transit time in shales obtained from the well $\log ; \Delta t_{n}$ is the transit time in shales at the normal pressure condition; $m$ is an exponent, and normally the exponent $m=3$ can be applied in the case that the overpressure was generated by undercompaction without any secondary mechanism of pore pressure generation.

The normal compaction trend or the transit time $\left(\Delta t_{n}\right)$ in normal pressure condition needs to be obtained in order to apply Eaton's sonic method. The following depth-dependent NCT equation can be used [9]:

$$
\Delta t_{n}=\Delta t_{m}+\left(\Delta t_{\mathrm{ml}}-\Delta t_{m}\right) e^{-c Z},
$$

where $\Delta t_{m}$ is the transit time in the shale matrix; $\Delta t_{\mathrm{ml}}$ is the transit time in the mudline (e.g., the transit time value when $Z=0$ ); $Z$ is the depth below the mudline; $c$ is the compaction parameter.

Alternatively, other sonic methods can be used for pore pressure calculation (e.g., [5, 9]). The following sonic method can also be used to calculate pore pressure gradient [9]:

$$
\begin{aligned}
P_{\mathrm{pg}} & \\
= & \text { OBG } \\
& \quad-\left(\text { OBG }-P_{\mathrm{ng}}\right) \frac{\ln \left(\Delta t_{\mathrm{ml}}-\Delta t_{m}\right)-\ln \left(\Delta t-\Delta t_{m}\right)}{c Z} .
\end{aligned}
$$

The geothermal gradient fuels the clay diagenesis reaction that takes place as the clay minerals of smectites transform to illite (e.g., [12, 13]). Therefore, shales in some areas (e.g., the Gulf of Mexico shelf) have different clay minerals as the burial depth increases. For example, the shale in a certain basin is mainly composed of smectite at a shallower depth, but the illite dominated at a deeper depth. The smectite to illite conversion (S-I) causes abnormal pressures [14]. Therefore, the normal compaction trends of the transit time should be different at different depths to account for the S-I conversion. Equation (4) can be used to obtain the multisegmental NCTs which have different compaction parameters $\left(c_{s}\right.$ and $\left.c_{i}\right)$, as shown in Figure 2; that is,

$$
\begin{aligned}
& \text { for smectite: } \Delta t_{s}=\Delta t_{m}+\left(\Delta t_{m l}-\Delta t_{m}\right) e^{-c_{s} Z} \\
& \text { for illite: } \Delta t_{i}=\Delta t_{m}+\left(\Delta t_{m l}-\Delta t_{m}\right) e^{-c_{i} Z} \\
& \text { for a linear } S-I \text { transition: } \Delta t_{t}=\left(\left(Z-Z_{1}\right) \Delta t_{i}+\left(Z_{2}-\right.\right. \\
& \left.Z) \Delta t_{s}\right) /\left(Z_{2}-Z_{1}\right),
\end{aligned}
$$

where $c_{s}, c_{i}$ are the compaction parameters for the smectite and illite, respectively; $Z_{1}$ is the depth of the smectite; $Z_{2}$ is the depth of the illite; $Z_{1}$ and $Z_{2}$ can be determined from mineral test results in offset wells or from the regional temperature profile which is associated with $S-I$ transitions.

Again, prior to applying the sonic method to the realtime detection, the normal compaction trend (NCT) needs to be obtained from (4) and (5) and to be calibrated to the offset well data. Then, this NCT is ready for the real-time application.

2.3. Corrected d-Exponent Method. It has been found that the rate of penetration (ROP) increases when drilling into an undercompacted shale or a shale with an abnormal pore pressure. That is, an increased rate of penetration may be indicative of an abnormal increase in pore pressure. However, there are also many other factors affecting ROP, such as the lithology, differential pressure, weight of the bit, rotating speed, torque, bit type, and change of bits. Therefore, the ROP is too random to be used as a detection method for abnormal pore pressure [15]. Instead, $d$-exponent can be used as one of the real-time pore pressure detection methods. Jorden and Shirley [16] proposed the following $d$-exponent equation:

$$
D_{x}=\frac{\log (\mathrm{ROP} / 60 N)}{\log \left(12 W / 10^{6} \mathrm{D}\right)},
$$




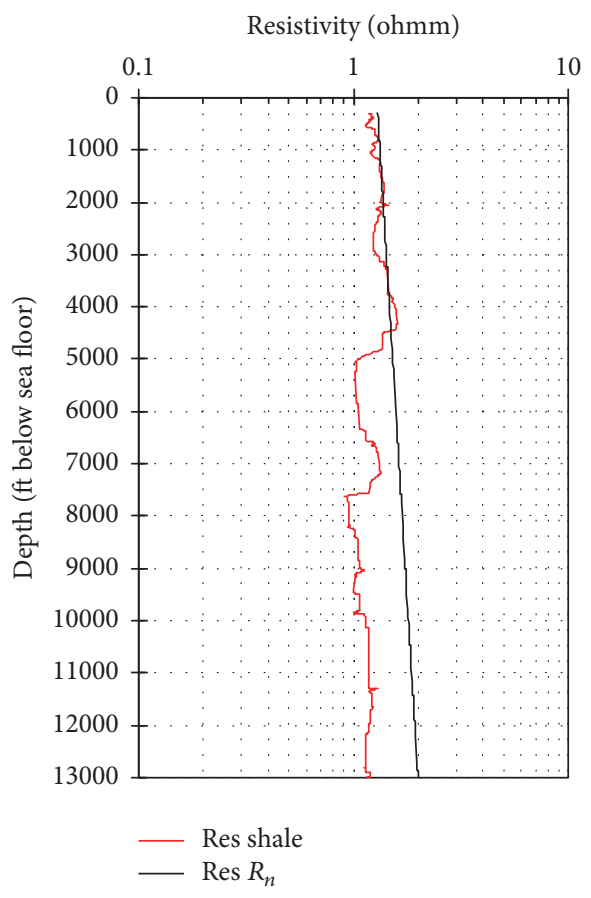

(a)

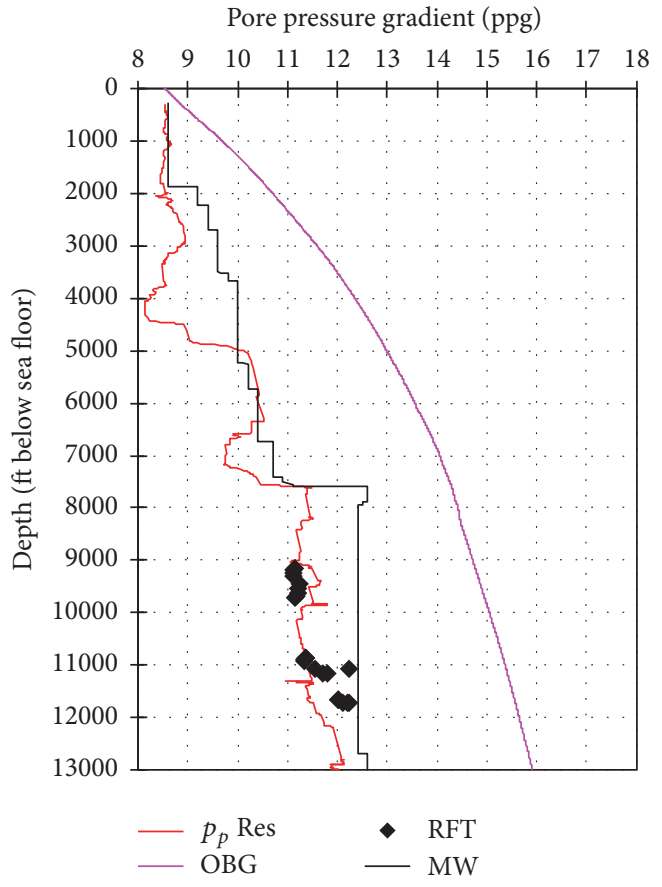

(b)

FIGURE 1: Measured and calculated pore pressure gradient and NCT calculated from the resistivity method ((1)-(2)).

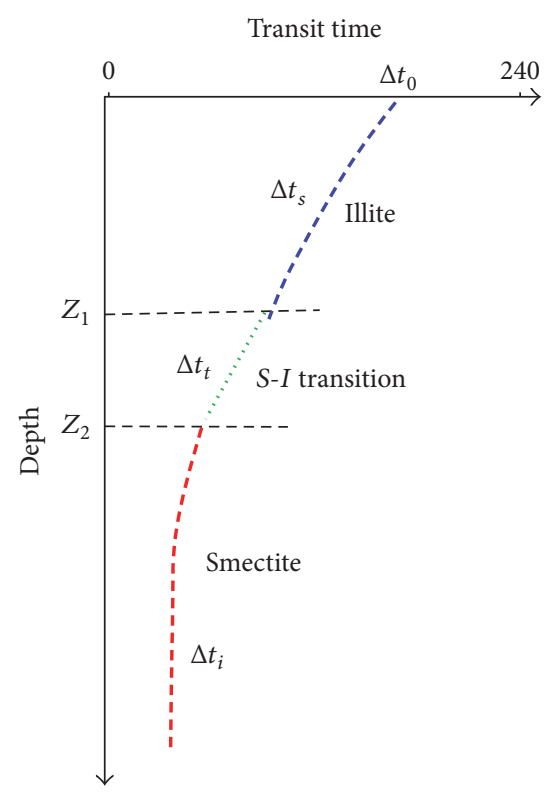

(a)

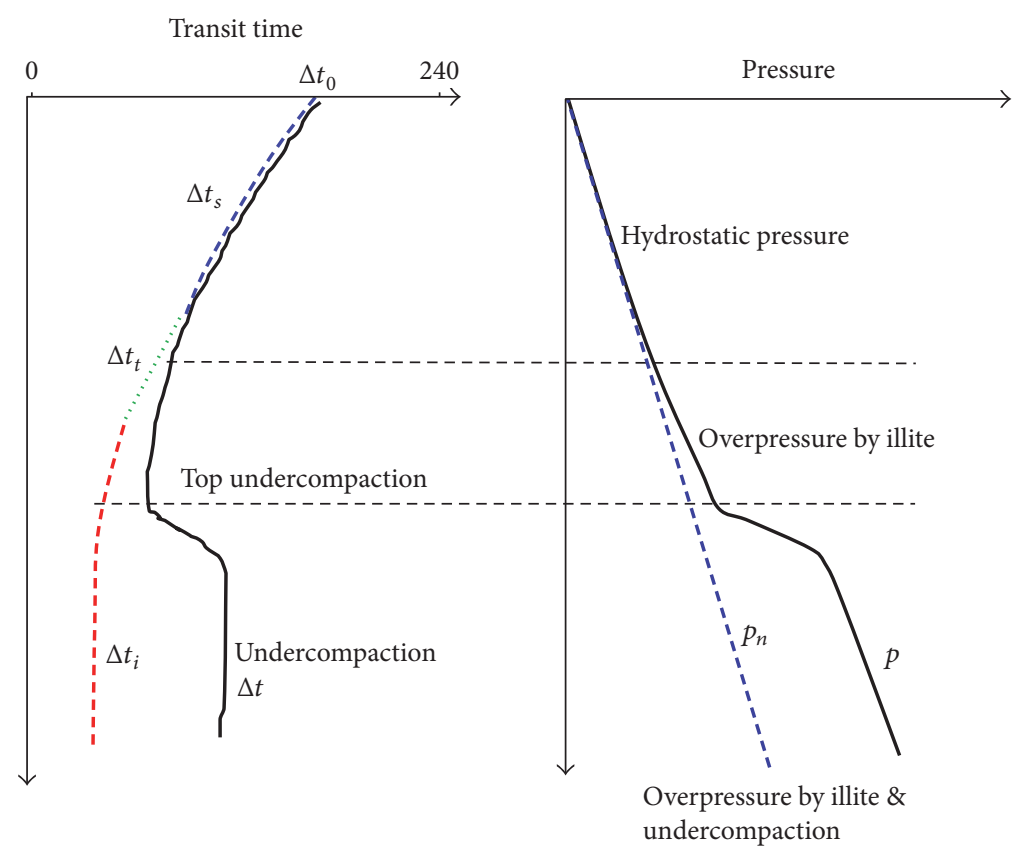

(b)

(c)

Figure 2: NCTs in the transit time versus the depth for the shale composed of the smectite and illite. (a) Composite NCT; (b) composite NCT and transit time; (c) overpressures caused by smectite to illite conversion and undercompaction. 
where $D_{x}$ is the $d$-exponent equation; ROP is the rate of penetration (ft/hr); $N$ is the rotary speed (rpm); $W$ is the weight on bit (lbs); $D$ is the hole diameter (inches).

The $d$-exponent is highly dependent on the differential pressure, that is, the difference of mud pressure and pore pressure. If mud weight is changed, then the $d$-exponent will change. Therefore, $d$-exponent needs to be corrected to reflect the change of mud weight. Rehm and McClendon [17] suggested the following correction:

$$
D_{x c}=D_{x} \frac{P_{\mathrm{ng}}}{P_{\mathrm{MW}}},
$$

where $D_{x c}$ is the corrected $d$-exponent equation; $P_{\mathrm{MW}}$ is the downhole mud weight, and the equivalent circulating density (ECD) is recommended for $P_{\mathrm{MW}}$ in pore pressure calculation; $P_{\text {ng }}$ is the hydrostatic pore pressure gradient.

Using the corrected $d$-exponent, the empirical equation [11] for pore pressure estimate can be written in the following form, which is similar to the resistivity method:

$$
P_{\mathrm{pg}}=\mathrm{OBG}-\left(\mathrm{OBG}-P_{\mathrm{ng}}\right)\left(\frac{D_{x c}}{D_{n}}\right)^{n},
$$

where $D_{n}$ is the shale $d$-exponent in the normal pressure condition; $n$ is the exponent, and normally $n=1.2$.

It should be noted that the $d$-exponent method initially was used for the rolling cutter bits. However, the PDC bits are widely used in the drilling industry. Because the PDCtype bits cut rocks with a shear cutting action instead of the chipping action that Jorden and Shirley [16] assumed in their chip-hold down model, the corrected $d$-exponent plots will differ from tricone or bicone bits in the same formation. Therefore, a careful calibration is needed prior to real-time applications of the corrected $d$-exponent method.

Determining normal $d$-exponent $\left(D_{n}\right)$ is a key step for using this method to calculate pore pressure in the real-time. We propose the following depth-dependent equation of the NCT for the corrected $d$-exponent:

$$
D_{n}=D_{0}+d Z,
$$

where $D_{0}$ is the shale $d$-exponent in the mudline; $d$ is the calibration parameter; $Z$ is the depth below the mudline. It should be noted that if the hole size, weight of bit, and other parameters change, the normal compaction trend may change.

For a normally compacted formation, porosity usually has an exponential relationship with depth [18]. Therefore, the following depth-dependent exponential equation of the NCT can also be used for the corrected $d$-exponent:

$$
D_{n}=D_{0} e^{d_{e} Z},
$$

where $d_{e}$ is a calibration constant.

In the same lithology, the corrected $d$-exponent gives a good indication of the state of compaction and pore pressure [15]. To reduce lithology effect in different lithologies, we only use the corrected $d$-exponents in shales for the pore pressure detection. Figure 3 presents a shale gas well for applying the corrected $d$-exponent method to estimate pore pressure by using the proposed depth-dependent NCT. After calibrations, this NCT can be used for the real-time pore pressure detection.

The big advantage of this method is that the parameters needed for calculation are obtained or measured from the drill bit (the BHA). Therefore, the pore pressure obtained from the corrected $d$-exponent method reflects the pore pressure near the bottom of the hole. The other advantage is that it can be used even in the case where there is no LWD data. It should be noted that this method is not applicable for the controlled drilling (e.g., controlled ROP). Based on the limitation of the $d$-exponent (highly dependent on ROP, lithology, bits, and hole size), this method should be associated with other methods for the real-time pore pressure detection.

\section{Abnormal Pore Pressure Indicators and Detection in Real-Time Drilling}

Well influx (including kicks, blowouts) and mud losses are potential risks for drilling operations, particularly for the well with a narrow mud weight window. Real-time pore pressure monitoring can constrain and update the predrill model to reduce uncertainties of pore pressure prediction and reduce drilling risks. Real-time pore pressure detection can be performed either on the rig site or remotely with the access of the real-time data. The real-time data for pore pressure detection mainly include LWD resistivity and sonic transit time, mud gas log, and drilling parameters (for calculating $D_{x c}$ ). The pore pressure measurement while drilling is important for calibrating real-time pore pressure model. The other calibration data includes mud logging data and drilling monitoring data, such as gas monitoring (total gas, trip gas, and connection gas), ROP, PWD (pressure while drilling), ECD (equivalent circulation density), ESD (equivalent static density) monitoring, hole fill monitoring, torque and drag, cuttings and cavings, well flow, and mud losses. Abnormal changes in these data may be related to an abnormal pore pressure, but they could also be caused by other factors (e.g., changes of lithology, salinity, temperature, hole size, and mud weight). Therefore, it is necessary to use all available data to analyze and interpret the indicators of abnormal pore pressure.

3.1. Procedures of Real-Time Pore Pressure Detection. For realtime pore pressure detection and monitoring, the following steps can be performed:

(1) Construct predrill petrophysical and pore pressure model as introduced in Section 2 and calibrate the predrill model to offset wells if they are available. The model includes methods of resistivity, sonic, Dxc, and so on. The model should include uncertainties and address drilling challenges and potential issues.

(2) Apply the model to the real-time well. It particularly needs to have a calibrated NCT for each method.

(3) Connect the model to real-time data (e.g., use ConnectML WITS and ConnectML WITSML to connect 


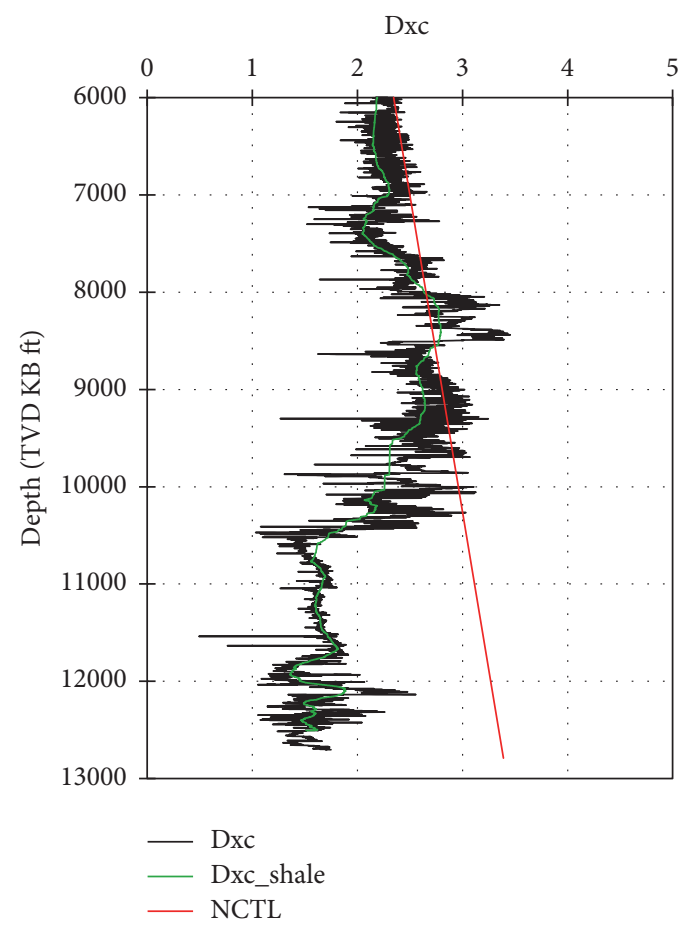

(a)

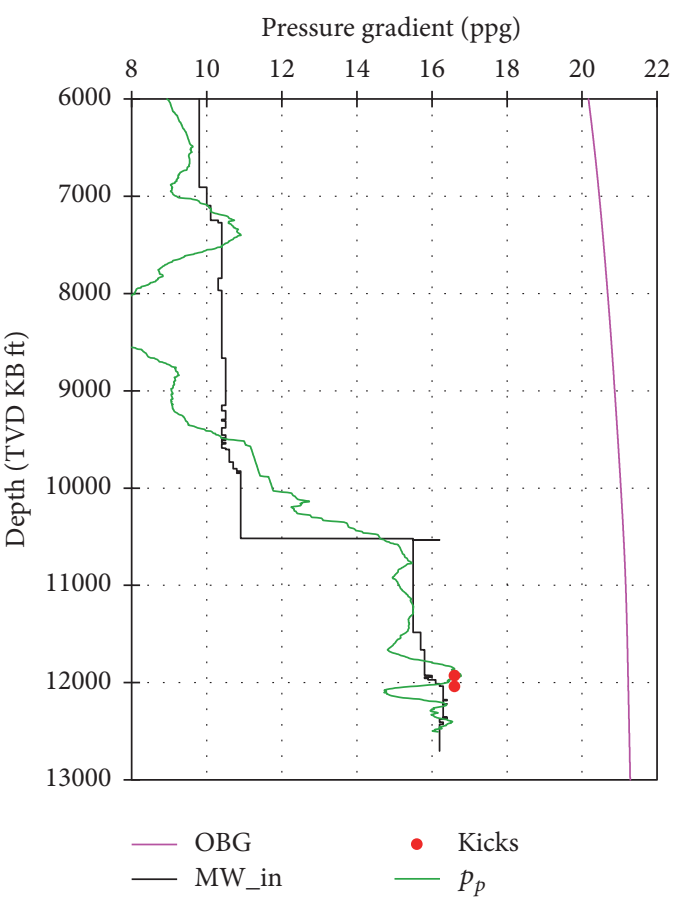

(b)

FIGURE 3: Pore pressure obtained from the corrected $d$-exponent method with depth-dependent compaction trend line in a shale gas well. (a) plots the corrected $d$-exponent in shale and the normal corrected $d$-exponent calculated from (9) with $D_{0}=1.5$ and $d=0.00015$. (b) shows the overburden gradient, mud weight, kicks, and pore pressure gradient calculated from the corrected $d$-exponent (see (8)).

LWD and MWD tools), so that the real-time data can be automatically loaded to the model. The model can then automatically calculate pore pressures based on the NCT using the real-time LWD and MWD data.

(4) Compare the real-time calculated pore pressure to downhole mud weight (ESD, ECD); to determine if the mud weight is sufficient, particularly it needs to identify whether or not the mud weight is less than the pore pressure gradient. Only comparing the real-time calculated pore pressure gradient to the mud weight is not enough to conclude an underbalanced drilling status. Therefore, it also needs to combine to other real-time indicators of pore pressures.

(5) Adjust the models (mainly NCTs) based on the following data if they are available: real-time pore pressure measurement, well influx, mud pit gains, kicks, mud gas data, mud losses, drilling parameters, and borehole instability events (e.g., cavings, torque, fills, and pack-offs).

(6) Alert and inform the rig for action when the pore pressure is lower (underbalanced) or close to the downhole mud weight.

(7) Liaise with technical expert group on all issues related to unplanned drilling operations, ECD, and pore pressures.

(8) Make postwell knowledge capture and transfer within the appropriate organizations and systems.
The real-time monitoring should ensure that

(1) pore pressure is continuously monitored and indicators of the abnormal pressures are identified;

(2) real-time pore pressure methods, estimates, and updates are discussed routinely with all involved monitoring parties to provide a consistent interpretation to the rig operations;

(3) abnormal pore pressure events are identified as soon as possible;

(4) the abnormal events, including significant observations, changes, or updates in pore pressure estimates, if they are occurring or imminent, need to be communicated to the operations (e.g., operation geologist and drilling engineer) quickly;

(5) the appropriate actions of operations (e.g., raising mud weight when the pore pressure gradient is lower than the downhole mud weight) are taken quickly.

3.2. Indicators from LWD Logs. The primary methods for real-time pore pressure calculation are the well-logs-based methods (i.e., from LWD resistivity and sonic transit time) as described in the previous section, and the resistivity log is normally available in the real-time. General rule for LWDbased prediction is that the decrease in resistivity or increase in transit time (which is not caused by the hydrocarbon presence) compared to the NCT is indicative of pore pressure increase. The normal compaction trends (NCT) are very 


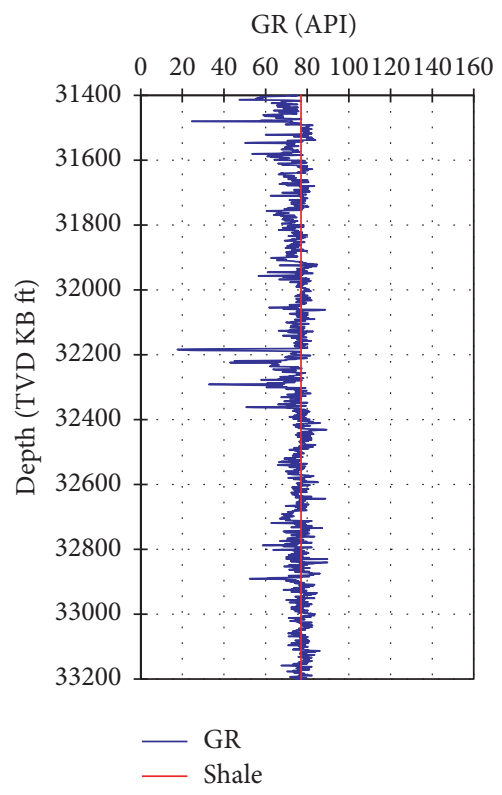

(a)

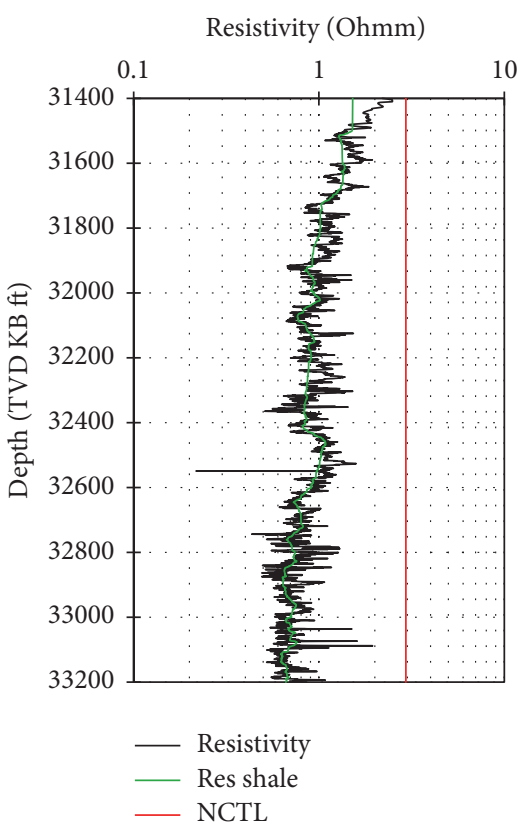

(b)

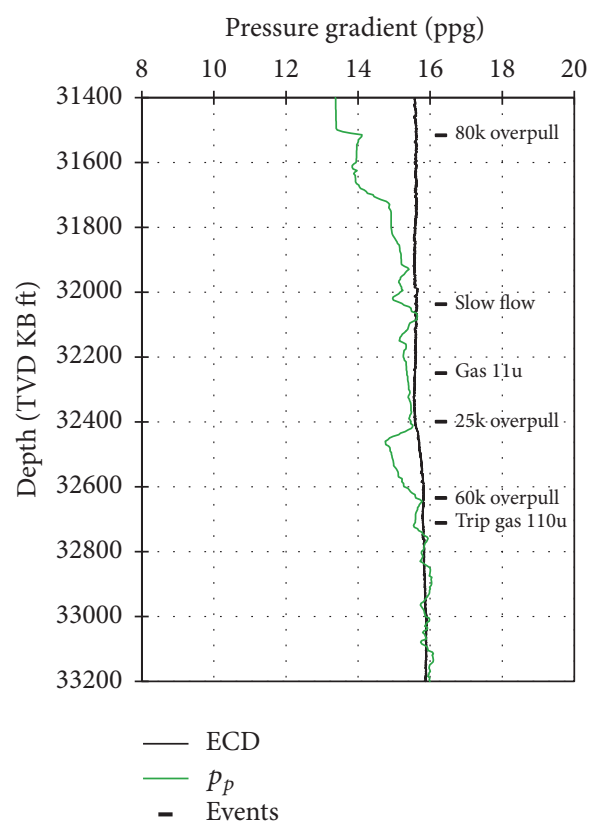

(c)

FIGURE 4: Real-time pore pressure detection from LWD resistivity. (a) shows the real-time gamma ray and shale lines; (b) presents the resistivity (red curve), picked shale resistivity (green curve), and NCT (red line); (c) plots the real-time calculated pore pressure (green curve), ECD, and drilling events (overpull, well influx, and mud gas indicators).

critical for applying these methods. The NCT should be properly calibrated from the offset wells prior to drilling. A fine adjustment of the NCT may be needed in real-time based on real-time pore pressure indicators. It should be noted that the LWD sensors have certain distances behind the bit (e.g., 20-100 ft, depending on the tools and BHA). Normally, the resistivity tool is closer to the drill bit than the sonic tool. Even using the resistivity data, the detected pore pressure from LWD logs is not the one at the bottom hole. Therefore, the log-based methods should be combined to other methods (e.g., Dxc method, in which the parameters are obtained from the bit measurements) to determine the pore pressure at the bit.

Figure 4 presents an example of real-time pore pressure monitoring from LWD resistivity in a deepwater well in the Gulf of Mexico, in which the NCT is obtained from the offset wells by using (2) and the pore pressure is calculated from (1) based on the NCT and real-time shale resistivity. The pore pressure result was used to guide drilling engineers for realtime mud weight adjustments. Wellbore fluid flow and trip gas below $32000 \mathrm{ft}$ in Figure 4 were due to a lower downhole MW (or ECD) than the formation pore pressure. The realtime calculated pore pressure was close to or higher than the ECD (Figure 4), meaning, in the permeable formation, that the formation fluid flow into the wellbore occurs. This is consistent with the abnormal pressure indication (well flow and trip gas show) observed in real-time.

3.3. Direct Indicators of Pore Pressure: Well Influx and Mud Losses. Well flow, mud pit gain because of well influx, and kicks are, normally, direct indicators of a higher pore pressure than the applied mud weight. In these cases, increasing the mud weight is needed. It should be noted that in these cases a well may not have fluid flow if the formations are impermeable (e.g., shales). In the impermeable formations, other indicators of underbalanced drilling status may be noticeable, such as wellbore instability (e.g., tight hole, caving, and pack-off). These indicators need to be analyzed to determine whether or not it is in underbalanced drilling status. If mud losses or lost circulation is observed, it normally indicates that the applied mud weight is higher than the fracture gradient (excluding mud losses into open fractures or vuggy zones); more details can be found in Zhang and Yin [19]; therefore, it may need to reduce the mud weight. When the hole ballooning occurs, it normally indicates that the mud weight is very close to the fracture gradient.

3.4. Indicators from the Mud Gas. Mud gas is an important indicator of the abnormal pore pressure in drilling operations, particularly in shale formations because of lack of good methods to measure the pore pressure in the shale. If large amounts of formation gas flow into the wellbore, the downhole mud weight is reduced because of the nature of low density of gas. This is "gas cut mud," indicating that the actual density of the mud coming out of the hole is less than the density of the mud being pumped into the hole. If the gas influx is large, the gas cut mud can cause a marked reduction of the downhole mud weight, and this could result in a gas kick or blowout. Therefore, the gas cut mud is an important indicator of the abnormal pore pressure. Connection and total gas measurements in mud logging have been used qualitatively for decades in drilling 


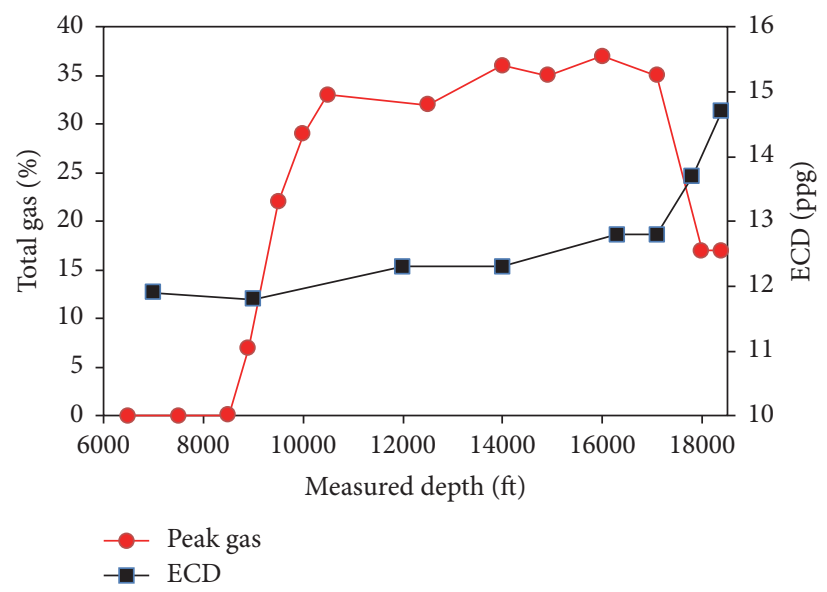

FIgURE 5: The total gas versus the downhole mud weight in a horizontal well (the estimated pore pressure from DFIT is $14.6 \mathrm{ppg}$ ).

oil and gas wells to identify overbalanced, underbalanced, or near underbalanced pressure conditions. Figure 5 plots the relationship of the downhole mud weight (ECD) and the peak total gas in a shale gas formation for an underbalanced drilling. The well was drilled horizontally when the borehole reached the shale gas formation at the vertical depth of $8500 \mathrm{ft}$. Figure 5 shows that when the ECD was at 12-12.7 ppg, the maximum total gas reached $37 \%$. When the ECD was increased and exceeded the pore pressure gradient (14.6 ppg), the total gas reduced markedly to $17 \%$. Therefore, mud gas data from mud logs can be used as an indicator of the abnormal pore pressure. General rule for the mud gas is that an increase in the mud gas relative to the background gas is an indication of pore pressure increasing. The drawback of this method is that mud gas data have a lag time behind the bit. That is, they are only available after the mud circulating the gas from the bottom hole (or the gas-bearing formation) to the surface, and the lag time can have several hours of delay depending on the hole depth. Six principles were proposed to quantitatively interpret mud gases relative to formation pore pressure [20]. These principles for total gas displays are restated as follows:

(i) normal background and no reported connection gases, then $P_{p}<$ Swab $<$ ESD $<$ ECD,

(ii) normal background and sporadic connection gases, then $\mathrm{Swab}<P_{p}<\mathrm{ESD}<\mathrm{ECD}$,

(iii) normal background and consistent connection gases, then $\mathrm{Swab}<\mathrm{ESD}<P_{p}<\mathrm{ECD}$,

(iv) elevated background and either sporadic or consistent connection gases, then $\mathrm{Swab}<\mathrm{ESD}<\mathrm{ECD}<P_{p}$,

(v) greatly elevated background and difficult to recognize connection gases, then Swab $<\mathrm{ESD}<\mathrm{ECD} \ll P_{p}$,

(vi) total gas drops in response to an ECD increase, then $P_{p}>$ ECD,

where Swab is the downhole swab pressure resulting from the drill string movement; $P_{p}$ is the pore pressure gradient; ESD is the equivalent static mud density; ECD is the equivalent circulating mud density.
3.5. Pore Pressure Calculation from the Connection Gas. Since mud gas is highly related to the pore pressure, we propose a new relationship to estimate pore pressure from the mud gas data based on Darcy's law. If the formation gas flows from the formation into the wellbore, then the formation pore pressure should be greater than the downhole mud pressure. We assume that the gas flow rate and the pressures follow Darcy's law; that is, they have the following linear relationship:

$$
q \propto \frac{k A}{\mu}\left(p_{p}-p_{\mathrm{MW}}\right)
$$

where $q$ is the gas flow rate; $k$ is the permeability; $A$ is the cross-sectional area of the flow; $\mu$ is the fluid viscosity; $p_{p}$ is the formation pore pressure; $p_{\mathrm{MW}}$ is the downhole mud pressure.

Not only is gas flow dependent on differential pressure as described by Darcy's law, but it may be also dependent on gas absorption and other factors. Here we adopt a simplified approach; that is, use (11) to describe gas flow from the formation into the wellbore. Assuming the connection gas is the gas flow, (11) can be simplified as the following form:

$$
p_{p}=a Q_{c}+p_{\mathrm{MW}}
$$

where $Q_{c}$ is the connection gas; $a$ is a calibration parameter.

If the total gas is very high, the connection gas may not be observed; however, elevated background gas may happen, and this indicates that the pore pressure is greater than the downhole mud pressure. Therefore, we can use the following equation to estimate pore pressure:

$$
p_{p}=c Q_{b}+p_{\mathrm{MW}},
$$

where $Q_{b}$ is the elevated background gas; $c$ is a calibration parameter.

Figure 6 presents a case of pore pressure calculation from the connection gas in a gas-bearing formation using (12). When the calibration data are available, constant $a$ or $c$ can be obtained; therefore, pore pressure can be estimated using the connection gas or elevated background gas. 


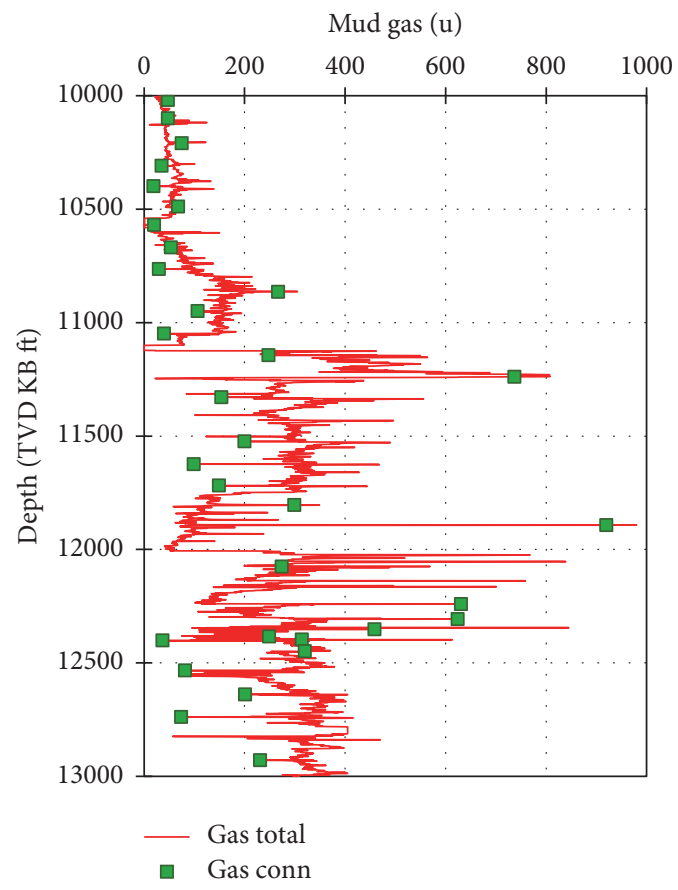

(a)

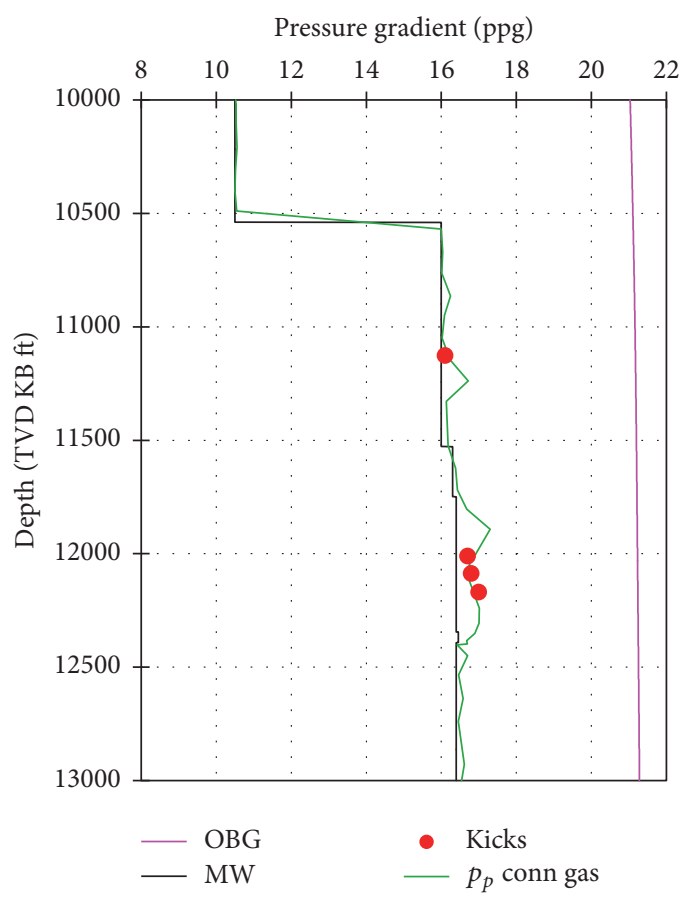

(b)

FIGURE 6: The pore pressure estimated from the connection gas using (12) in a shale gas well. (a) shows the total gas and connection gas (Gas conn); (b) presents the calculated pore pressures compared to the kicks, mud weight (MW), and overburden stress (OBG).

It should be noted that (12) and (13) describe the case where the downhole mud weight is lower than the pore pressure; that is, the borehole has gas influx from the formation (e.g., connection gas). Therefore, (12) and (13) can be applicable only if the downhole mud weight is lower than the pore pressure. Since natural gas is a compressible fluid, (11)-(13) are the approximate solutions for estimating pore pressures, and the calibration from other pore pressure methods or the observed data is needed. It should also be noted that the total gas and connection gas have lag time (depending on the depth). The lag time is the time from the gas coming out the formation at the bottom hole to be circulated with the mud to the gas trap (gas collector) on the drilling deck, and this lag time needs to be corrected for the pore pressure estimate.

3.6. Indicators from PWD. Identifying whether an underbalanced drilling status occurs or not is a key technique for real-time pore pressure detection. In the real-time measurements, the downhole mud weight data (ECD or ESD) can be obtained. The underbalanced drilling status can be identified through comparing the pore pressure gradient to the mud weight. A kick can be identified from the pressure while drilling (PWD) measurements-an abrupt increase in downhole pressure and temperature because the formation fluid flowing into the wellbore has a higher pressure than the mud pressure and a higher temperature than the mud temperature. Figure 7 shows that a shale gas well was drilled with a constant surface mud weight and a near-constant downhole mud weight (ECD) initially. However, the PWD increases rapidly owing to a kick, in which the formation fluid flows into wellbore with a much higher formation pressure than the downhole mud pressure and a much higher formation temperature than the downhole mud temperature. Therefore, well influx can be identified through analyzing the downhole measured mud pressure and temperature.

3.7. Indicators from Wellbore Instability. When the mud weight is inappropriate, wellbore instability events occur while drilling, which can help to diagnose the overpressure and to adjust mud weight in real-time drilling operations. Wellbore instability can be classified into two categories: shear and tensile failures. When the downhole mud weight is less than the shear failure gradient (SFG, or borehole collapse pressure gradient), the wellbore experiences shear failure $[21,22]$. Shear failure is mainly caused by the condition in which the applied mud weight is lower than the SFG. The indicators of shear failures while drilling include hole enlargement (borehole breakout), hole closure, tight hole (overpull), high toque, hole fill after trip, hole bridging, hole pack-off, and hole collapse [23]. Some of these indicators may be caused by a swelling shale when the water-based mud is used because of the chemical reaction between the mud and the shale formation. Therefore, it needs to identify the causes of the failures.

Here we use a vertical well as an example to illustrate the relationship of wellbore instability and pore pressure. Based on Mohr-Coulomb failure criterion, the minimum 


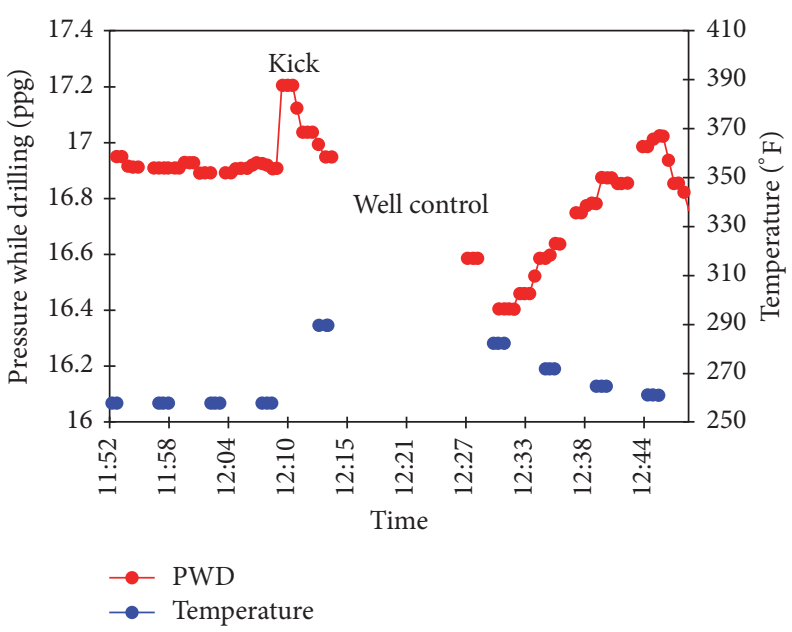

FIGURE 7: Well influx/kick detected from pressure while drilling showing an abrupt increase in measured downhole pressure (PWD or ECD) and temperature.

mud weight to avoid borehole shear failure can be obtained from the following equation [21]:

$$
p_{m}=\frac{1-\sin \varphi}{2}\left(3 \sigma_{H}-\sigma_{h}-\mathrm{UCS}\right)+p_{p} \sin \varphi
$$

where $p_{m}$ is the minimum mud pressure or collapse (shear failure) pressure, $\varphi$ is the angle of friction of the rock; UCS is the rock uniaxial compressive strength; $\sigma_{H}, \sigma_{h}$ are the maximum and minimum horizontal stresses, respectively. The horizontal stresses are most important parameters for analyzing wellbore stability, which can be obtained from either field measurements or calculations (e.g., [24]).

Equation (14) shows that the shear failure is directly related to the pore pressure; a higher pore pressure needs a heavier mud weight to keep the wellbore from the shear failure. Therefore, wellbore instability can be used as an indicator of an overpressured formation.

Tensile failure, however, occurs when the mud pressure exceeds the capacity of the near-wellbore rock to bear tensile stress. If the downhole mud weight is higher than the fracture gradient, the formation will be fractured to create hydraulic fractures (or drilling-induced tensile fractures). Real-time indicators of drilling-induced tensile failures include hole ballooning, drilling mud losses, and lost circulation. Reducing mud weight, adding lost circulation materials (LCM), or applying wellbore strengthening technique are possible cures for the drilling-induced tensile failures.

3.8. Indicators from Abnormal Cuttings. General rule is that the insufficient mud weight produces more and larger cuttings. There are generally four types of cuttings-normal cuttings, cuttings from preexisting fractures, cuttings owing to underbalanced drilling, and cuttings owing to shear failures.

(1) Normal Cuttings. If the mud weight is appropriate, that is, higher than pore pressure and collapse pressure but lower than the fracture gradient, the wellbore is in a good condition.
In this case, normal cuttings are generated with PDC cutting marks when a PDC bit is used, as shown in Figure 8(a).

(2) Cuttings from Preexisting Fractures. In a formation with preexisting fractures or in a faulted section, the rock may have a lower compressive strength and lower fracture gradient. In this case, it may generate blocky cuttings in which the naturally fractured planes may be observed; therefore, mud losses probably occur in the preexisting fractures. Figure 8(b) presents a picture of blocky cuttings in a subsalt formation where mud losses occurred.

(3) Cuttings Owing to Underbalanced Drilling. If the downhole mud weight is less than the formation pore pressure gradient, the wellbore experiences splintering failure or spalling. In this case, spiky and concaved cavings are generalized, as shown in Figure 9, and wellbore collapse and fluid kick (if a permeable formation is encountered) may occur.

(4) Cuttings Owing to Shear Failures. Shear failures cause angular or splintered cavings in the wellbore. In this case, the rock failure of the wellbore is similar to a triaxial compressive core test, where angular or splintered rock pieces are formed, as shown in Figure 10.

3.9. Summary of Real-Time Indicators for Abnormal Pore Pressures. As stated in the previous sections, Table 1 summarizes the indicators of abnormal pore pressures in the realtime monitoring. These indicators can be used to identify abnormal pore pressures and to calibrate and update the realtime pore pressure models.

\section{Conclusions}

For the real-time pore pressure detection, a real-time pore pressure model needs to firstly be built based on all available data in offset wells, and then all real-time abnormal pressure indicators need to be incorporated to calibrate the model. The real-time pore pressure model mainly includes LWD-based 


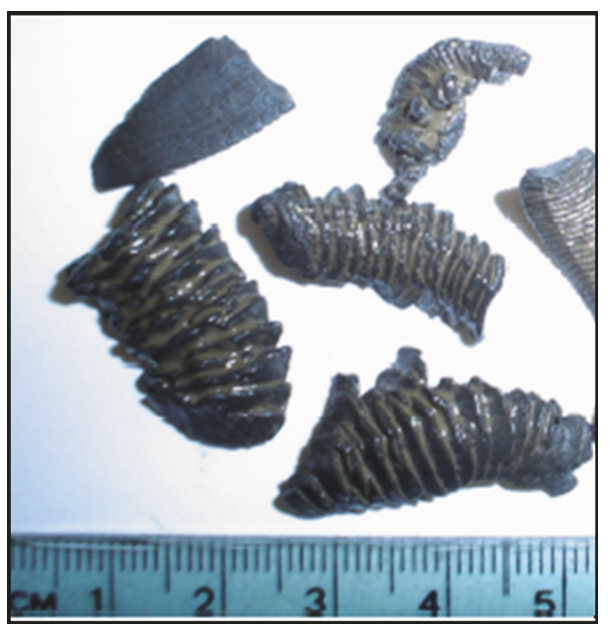

(a)

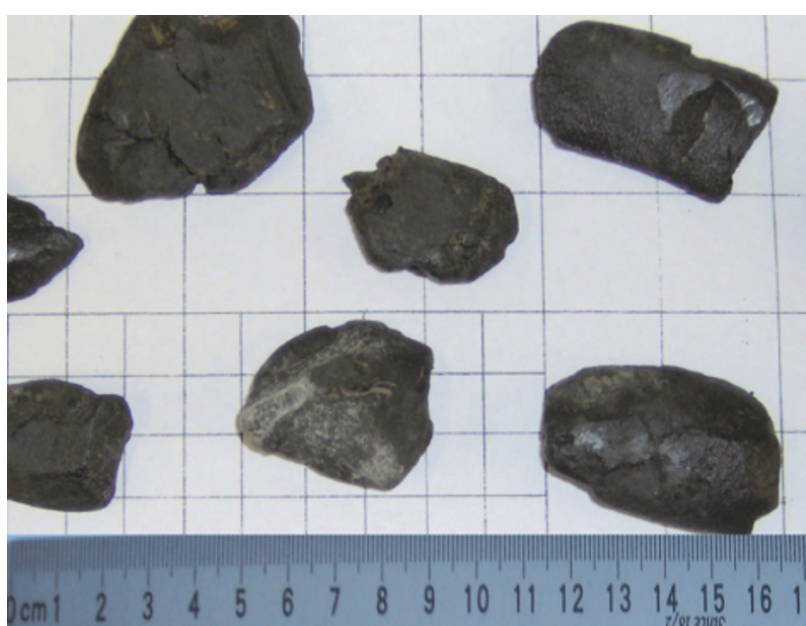

(b)

FIGURE 8: Drilling cuttings. (a) Normal PDC cuttings of shales; (b) blocky cuttings from a formation with preexisting fractures.

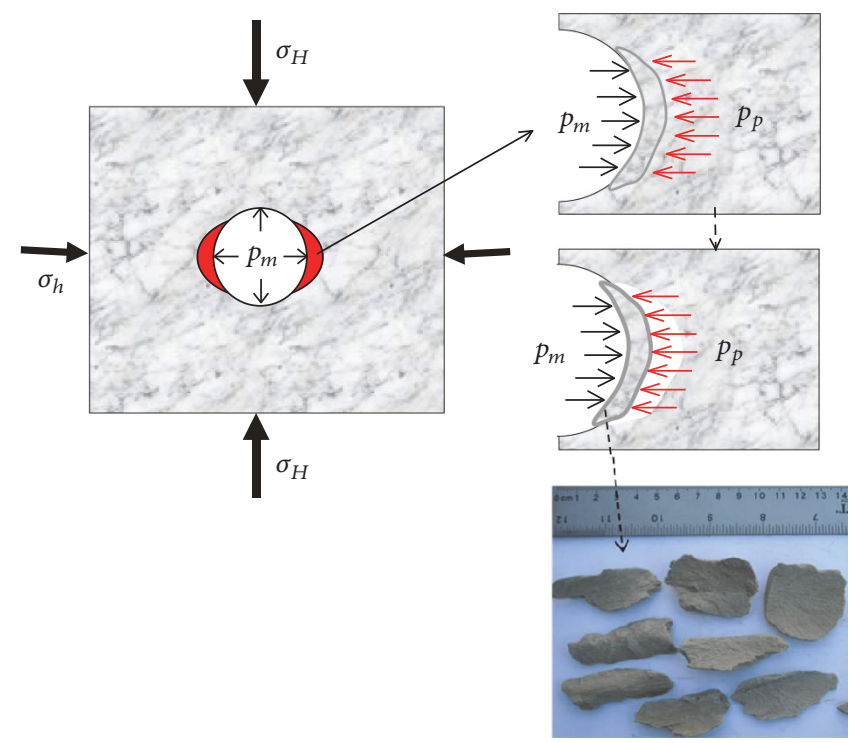

FIGURE 9: Schematic representation of wellbore spalling/chips for a higher pore pressure than the mud pressure (underbalanced drilling condition) in a vertical borehole. Upper part illustrates the high pore pressure that blows rock chips into wellbore; the bottom picture shows spiky and concaved cuttings resulting from the insufficient mud weight.

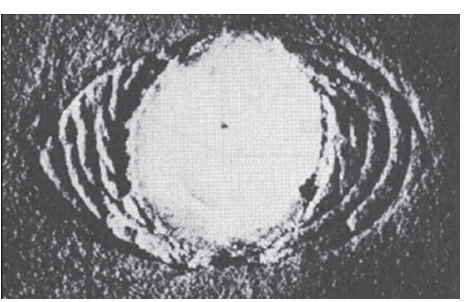

(a)

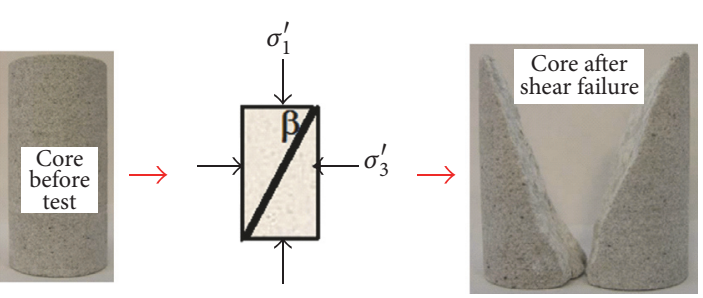

(b)

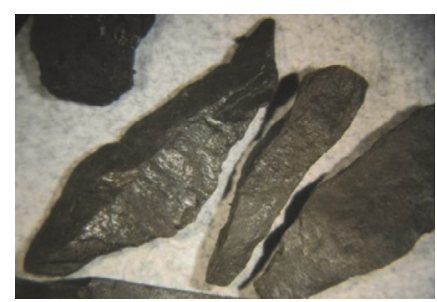

(c)

FIGURE 10: Angular or splintered cavings caused by shear failures: a case of lower mud weight than the shear failure gradient. (a) Borehole breakout from shear failure in a laboratory test [25]; (b) triaxial compressive core test creating angular rock pieces; (c) angular/splintered cavings from a subsalt borehole. 
TABLE 1: Real-time indicators of abnormal pore pressures.

\begin{tabular}{|c|c|}
\hline Indicators & General behaviors \\
\hline Total gas & Total gas should increase when an underbalanced drilling occurs in a gas-bearing formation. \\
\hline Background gas & $\begin{array}{l}\text { Background gas should increase with ROP. For a constant ROP, background gas is expected to increase as } \\
\text { the pore pressure increases. }\end{array}$ \\
\hline $\begin{array}{l}\text { Connection gas and } \\
\text { pump-off gas }\end{array}$ & $\begin{array}{l}\text { Connection gas, swab gas, or pumps-off gas occurring may indicate that the pore pressure is higher than } \\
\text { the ESD. }\end{array}$ \\
\hline Gas cut mud & Gas cut mud is a sign of abnormal pore pressure and underbalanced drilling. \\
\hline ROP & ROP increase may indicate the pore pressure gradient increasing. \\
\hline Dxc & $\begin{array}{l}\text { Gradual decrease in Dxc compared to its NCT may indicate the pore pressure gradient increasing } \\
\text { (Figure 11). }\end{array}$ \\
\hline Resistivity & $\begin{array}{l}\text { Gradual decrease in resistivity compared to its NCT may indicate the pore pressure gradient increasing } \\
\text { (Figure 11). }\end{array}$ \\
\hline DT & $\begin{array}{l}\text { Gradual increase in sonic transit time (DT) compared to its NCT may indicate pore pressure gradient } \\
\text { increasing (Figure 11). }\end{array}$ \\
\hline PWD and temperature & Sudden increase in PWD with increase of MWD temperature may indicate an influx or kick. \\
\hline Mud volume & Mud pit volume increasing may indicate a kick. \\
\hline Cuttings & $\begin{array}{l}\text { Increase in percentage of cuttings may indicate wellbore instability or abnormal pore pressure. Splintery } \\
\text { cavings may indicate underbalanced drilling, and large amounts of splintery and angular cavings indicate } \\
\text { a wellbore collapse. }\end{array}$ \\
\hline Hole fill & $\begin{array}{l}\text { Hole fills (i.e., cavings falling in) after connections indicate wellbore instability and it may need to increase } \\
\text { the mud weight. }\end{array}$ \\
\hline $\begin{array}{l}\text { High torque, overpull, tight } \\
\text { hole, pack-off }\end{array}$ & $\begin{array}{l}\text { Hole pack-off, overpull, tight hole, and increasing torque and drag are likely to be caused by a higher } \\
\text { collapse pressure or higher pore pressure than the mud weight. It needs to increase the mud weight. }\end{array}$ \\
\hline
\end{tabular}

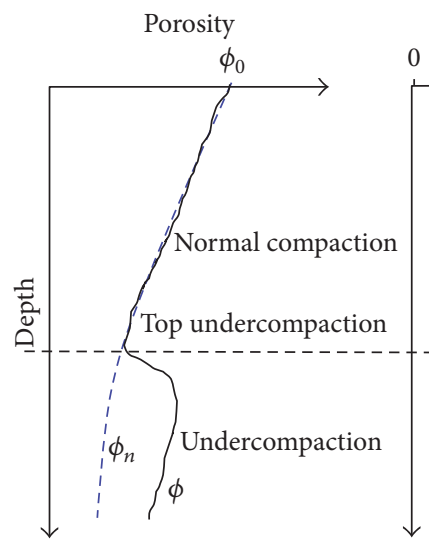

(a)

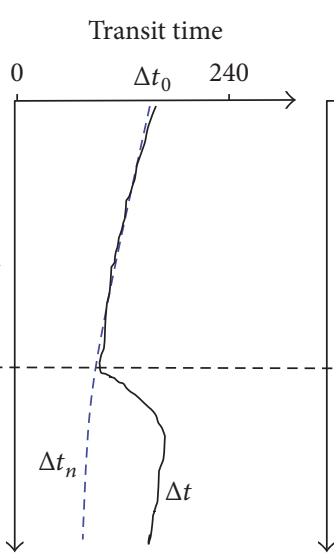

(b)

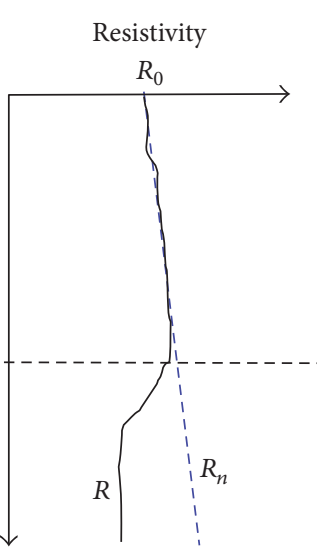

(c)

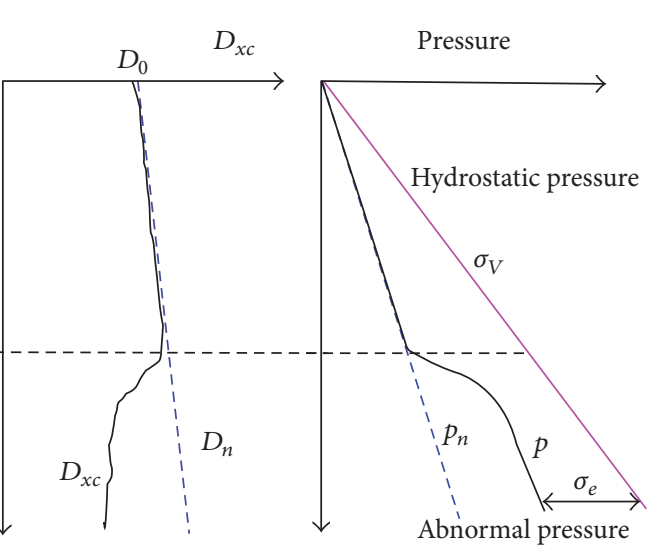

(d)

(e)

FiguRE 11: Generalized normal compaction trends (NCTs) and abnormal pressures caused by undercompaction. From (a) to (e): porosity, transit time, resistivity, $D$-exponent, and pore pressure plots.

(e.g., resistivity and sonic transit time) and MWD-based (e.g., Dxc) pore pressure detection methods. To apply these methods, the normal compaction trends are the key parameters. The new depth-dependent equations of the normal compaction trends for resistivity, sonic transit time, and Dxc are proposed, which provide a quantitative way to handle normal compaction trend lines. The normal compaction trend lines need to be calibrated to both offset data and the real-time measured pore pressures and other indicators to finalize the trend lines. To reduce uncertainties, the pore pressure model needs to integrate with the real-time measurements and indicators, such as real-time pore pressure measurements, well influx and kicks, mud logging (total gas, trip gas, and connection gas), MWD, ROP, ECD/ESD measurements, and borehole instability events (e.g., abnormal torque and drag, tight hole, abnormal cuttings or cavings, hole enlargement or breakout, hole fill, and pack-off).

A new method is proposed to calculate pore pressure from the connection gas and background gas. It can be used for real-time pore pressure interpretation, particularly for shale gas formations. It should be noted that some realtime measurements have lag time, for example, drill gas in 
mud logging and cuttings on the surface. The LWD sensors (such as resistivity and sonic tools) also have certain distances behind the drill bit. These disadvantages make it difficult for the real-time monitoring to detect the pore pressure at the bit (excluding Dxc). However, if a formation follows a certain compaction or undercompaction trend, then, the pore pressure at the bit can be interpolated.

\section{Disclosure}

Jincai Zhang is now with Sinopec Tech, Houston, USA.

\section{Conflicts of Interest}

The authors declare that there are no conflicts of interest regarding the publication of this paper.

\section{Acknowledgments}

This work was partially supported by the Program for Innovative Research Team in University sponsored by Ministry of Education of China (IRT-17R37), "Shisan Wu" China National Key R\&D Project (2017YFC0804108), and Natural Science Foundation of Hebei Province of China (D2017508099).

\section{References}

[1] G. Dickinson, "Geological aspects of abnormal reservoir pressures in gulf coast louisiana," AAPG Bulletin, vol. 37, no. 2, pp. 410-432, 1953.

[2] B. A. Eaton, "The effect of overburden stress on geopressure prediction from well logs," Journal of Petroleum Technology, vol. 24, no. 08, pp. 929-934, 1972.

[3] G. L. Bowers, "Pore pressure estimation from velocity data: accounting for overpressure mechanisms besides undercompaction," SPE Drilling \& Completion, vol. 10, no. 2, pp. 89-95, 1995.

[4] M. Traugott, "Pore pressure and fracture gradient determinations in deepwater," World Oil, 1997.

[5] G. L. Bowers, "Determining an appropriate pore-pressure estimation strategy," in Proceedings of the Offshore Technology Conference, Offshore Technology Conference, Houston, Tex, USA, 2001.

[6] P. B. Flemings, B. B. Stump, T. Finkbeiner, and M. Zoback, "Flow focusing in overpressured sandstones: Theory, observations, and applications," American Journal of Science, vol. 302, no. 10, pp. 827-855, 2002.

[7] M. R. P. Tingay, R. R. Hillis, R. E. Swarbrick, C. K. Morley, and A. R. Damit, "Origin of overpressure and pore-pressure prediction in the Baram province, Brunei," AAPG Bulletin, vol. 93, no. 1, pp. 51-74, 2009.

[8] S. Li, J. George, and C. Purdy, "Pore-pressure and wellborestability prediction to increase drilling efficiency," Journal of Petroleum Technology, vol. 64, no. 2, pp. 98-101, 2012.

[9] J. Zhang, "Pore pressure prediction from well logs: Methods, modifications, and new approaches," Earth-Science Reviews, vol. 108, no. 1-2, pp. 50-63, 2011.

[10] J. Zhang, "Effective stress, porosity, velocity and abnormal pore pressure prediction accounting for compaction disequilibrium and unloading," Marine and Petroleum Geology, vol. 45, pp. 211, 2013a.

[11] B. A. Eaton, "The equation for geopressure prediction from well logs," in Proceedings of the Fall Meeting of the Society of Petroleum Engineers of AIME, Society of Petroleum Engineers, Dallas, Tex, USA, 1975.

[12] W.-L. Huang, J. M. Longo, and D. R. Pevear, "An experimentally derived kinetic model for smectite-to-illite conversion and its use as a geothermometer," Clays and Clay Minerals, vol. 41, no. 2, pp. 162-177, 1993.

[13] R. Lahann, W. Lahann, D. McCarty, and J. Hsieh, "Influence of clay diagenesis on shale velocities and fluid-pressure," in Proceedings of the Offshore Technology Conference, Offshore Technology Conference, Houston, Tex, USA, 2001.

[14] R. W. Lahann and R. E. Swarbrick, "Overpressure generation by load transfer following shale framework weakening due to smectite diagenesis," Geofluids, vol. 11, no. 4, pp. 362-375, 2011.

[15] J.-C. Mouchet and A. Mitchell, Abnormal Pressures While Drilling, Editions TECHNIP, Paris, France, 1989.

[16] J. Jorden and O. Shirley, "Application of drilling performance data to overpressure detection," Journal of Petroleum Technology, vol. 18, no. 11, pp. 1387-1394, 2013.

[17] B. Rehm and R. McClendon, "Measurement of formation pressures from drilling data," Paper SPE, p. 3601, 1971.

[18] L. F. Athy, "Density, porosity, and compaction of sedimentary rocks," AAPG Bulletin, vol. 14, no. 1, pp. 1-24, 1930.

[19] J. Zhang and S. Yin, "Fracture gradient prediction: an overview and an improved method," Petroleum Science, pp. 1-11, 2017.

[20] M. Alberty and K. Fink, in Proceedings of the SPE Annual Technical Conference and Exhibition, Society of Petroleum Engineers, New Orleans, La, USA, 2013.

[21] J. Zhang, "Borehole stability analysis accounting for anisotropies in drilling to weak bedding planes," International Journal of Rock Mechanics and Mining Sciences, vol. 60, pp. 160-170, 2013b.

[22] J. Zhang, J. Lang, and W. Standifird, "Stress, porosity, and failure-dependent compressional and shear velocity ratio and its application to wellbore stability," Journal of Petroleum Science and Engineering, vol. 69, no. 3-4, pp. 193-202, 2009.

[23] J. Lang, S. Li, and J. Zhang, "Wellbore stability modeling and real-time surveillance for deepwater drilling to weak bedding planes and depleted reservoirs," in Proceedings of the SPE/IADC Drilling Conference and Exhibition, 2011.

[24] Y. Zhang and J. Zhang, "Lithology-dependent minimum horizontal stress and in-situ stress estimate," Tectonophysics, vol. 703-704, pp. 1-8, 2017.

[25] M. Addis, N. Barton, S. Bandis, and J. Henry, "Laboratory studies on the stability of vertical and deviated boreholes," in Proceedings of the SPE Annual Technical Conference and Exhibition, Society of Petroleum Engineers, New Orleans, La, USA, September 1990. 

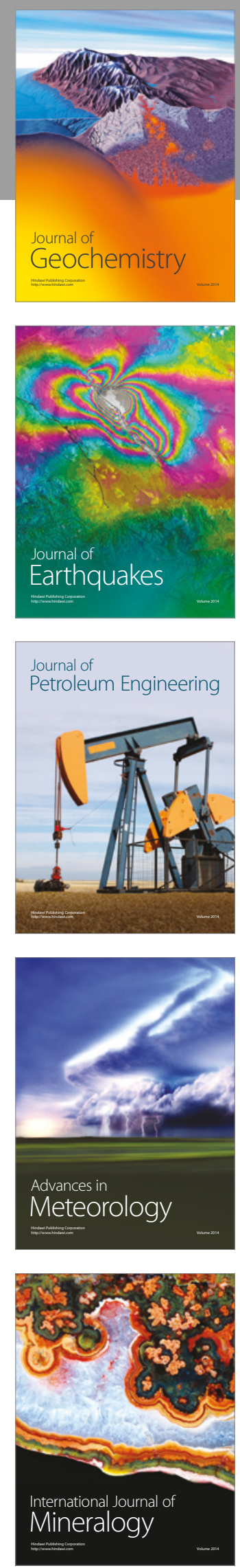
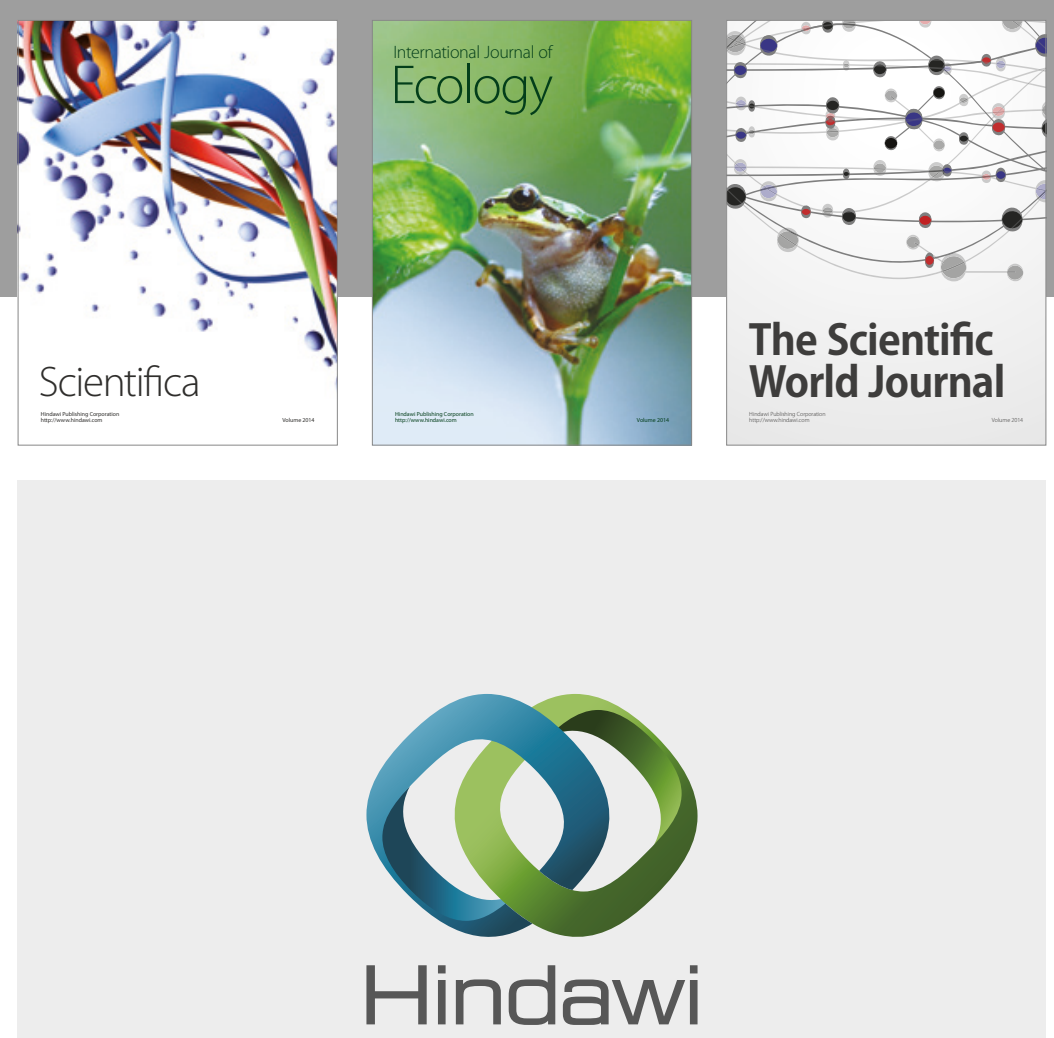

Submit your manuscripts at

https://www.hindawi.com
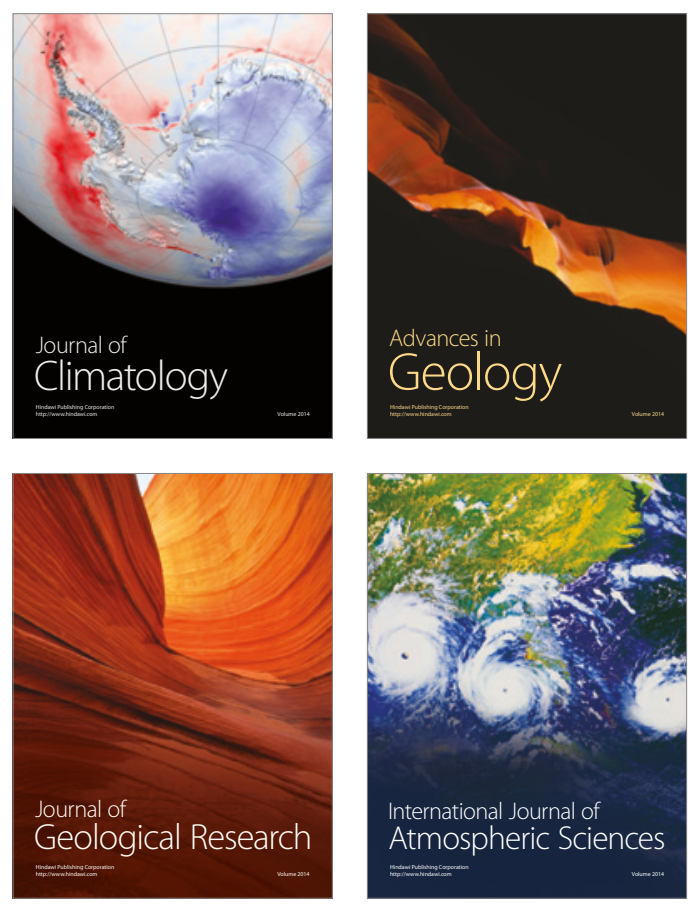

The Scientific

World Journal
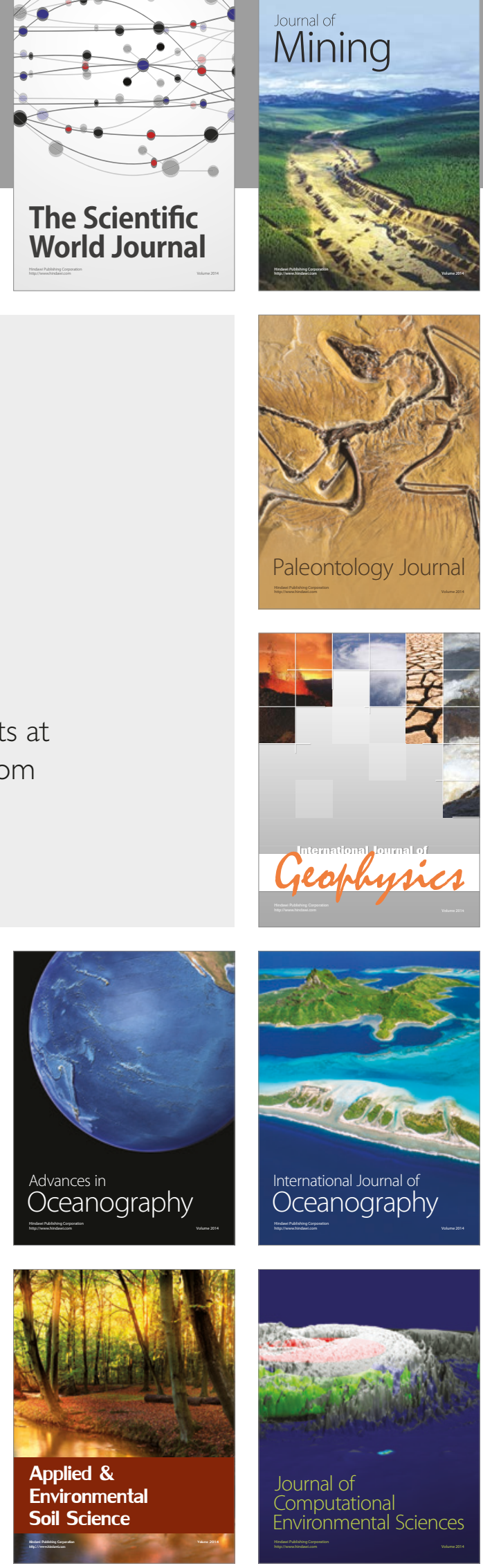